Proceedings of the 4th Asia-Pacific BIOINFORMATICS Conference 


\section{SERIES ON ADVANCES IN BIOINFORMATICS AND COMPUTATIONAL BIOLOGY}

\section{Series Editors:}

Ying XU (University of Georgia, USA)

Limsoon WONG (National University of Singapore, Singapore)

\section{Associate Editors:}

Ruth Nussinov (NCI, USA)

Rolf Apweiler ( $E B I, U K)$

See-Kiong Ng (Inst for Infocomm Res, Singapore)

Ed Wingender (BioBase, Germany)

Kenta Nakai (Univ of Tokyo, Japan)

Mark Ragan (Univ of Queensland, Australia)

Vol. 1: Proceedings of the 3rd Asia-Pacific Bioinformatics Conference Eds: Yi-Ping Phoebe Chen and Limsoon Wong

Vol. 2: Information Processing and Living Systems Eds: Vladimir B. Bajic and Tan Tin Wee

Vol. 3: Proceedings of the 4th Asia-Pacific Bioinformatics Conference Eds: Tao Jiang, Ueng-Cheng Yang, Yi-Ping Phoebe Chen and Limsoon Wong 
Series on Advances in Bioinformatics and Compurational Biology - Volume 3

Proceedings of the 4th asia-Pacific

\section{BIOINFORMATICS \\ Conference}

Taipei, Taiwan $13-16$ February 2006

EdITORS

\section{Tao Jiang}

University of California, Riverside, USA

Ueng-Cheng Yang

Narional Yang-Ming University, Taiwan

\section{Yi-Ping Phoebe Chen \\ Deakin University, Australia}

\section{LimsOON WONG}

National University ol Singapore, Singapore 
Published by

Imperial College Press

57 Shelton Street

Covent Garden

London WC2H 9HE

\section{Distributed by}

World Scientific Publishing Co. Pte. Ltd.

5 Toh Tuck Link, Singapore 596224

USA office: 27 Warren Street, Suite 401-402, Hackensack, NJ 07601

UK office: 57 Shelton Street, Covent Garden, London WC2H 9HE

\section{British Library Cataloguing-in-Publication Data}

A catalogue record for this book is available from the British Library.

\section{PROCEEDINGS OF THE 4TH ASIA-PACIFIC BIOINFORMATICS CONFERENCE}

Copyright $\bigcirc 2006$ by Imperial College Press

All rights reserved. This book, or parts thereof, may not be reproduced in any form or by any means, electronic or mechanical, including photocopying, recording or any information storage and retrieval system now known or to be invented, without written permission from the Publisher.

For photocopying of material in this volume, please pay a copying fee through the Copyright Clearance Center, Inc., 222 Rosewood Drive, Danvers, MA 01923, USA. In this case permission to photocopy is not required from the publisher

ISBN $\quad 1-86094-623-2$

Printed by FuIsland Offset Printing (S) Pte Ltd, Singapore 


\section{PREFACE}

High-throughput sequencing and functional genomics technologies have given us a draft human genome sequence and have enabled large-scale genotyping and gene expression profiling of human populations. Databases containing large numbers of sequences, polymorphisms, and gene expression profiles of normal and diseased tissues in different clinical states are rapidly being generated for human and model organisms. Bioinformatics is thus rapidly growing in importance in the annotation of genomic sequences, in the understanding of the interplay between genes and proteins, in the analysis the genetic variability of species, etc.

The Asia-Pacific Bioinformatics Conference series is an annual forum for exploring research, development, and novel applications of Bioinformatics. It brings together researchers, professionals, and industrial practitioners for interaction and exchange of knowledge and ideas. The Fourth Asia-Pacific Bioinformatics Conference, APBC2006, was held in Taipei 13-16 February, 2006. Taking advantage of the presence of APBC 2006 in Taipei, several related activities were also organized immediately before or after APBC 2006, including the Third Association of Asian Societies for Bioinformatics Symposium.

A total of 118 papers were submitted to APBC 2006. These submissions came from China, Hong Kong, India, Japan, Korea, Singapore, Taiwan, Australia, Belgium, France, Germany, Italy, Norway, Russia, UK, Canada, and USA. We assigned each paper to at least 3 members of the programme committee. Although not all members of the programme committee managed to review all the papers assigned to them, a total of 340 reviews were received. As a result, there were almost 2.9 reviews per paper on average, and more than $98 \%$ of the papers received at least 3 reviews.

A total of 35 papers (i.e. $30 \%$ ) were accepted for presentation and publication in the proceedings of APBC 2006. Each accepted papers had at least 2 positive recommendations and no negative recommendations from their reviewers. Based on the affiliation of the authors, 1.80 of the accepted papers were from China, 4.50 were from Hong Kong, 3.00 were from India, 3.50 were from Japan, 0.75 were from Korea, 3.00 were from Singapore, 3.00 were from Taiwan, 2.00 were from Australia, 3.20 were from Canada, 7.25 were from USA, 1.00 were from France, 1.00 were from Germany, and 1.00 were from Norway. In addition to the accepted papers, the scientific programme of APBC 2006 also included 3 keynote talks, as well as tutorial and poster sessions. There is no 
doubt that the presentations covered a broad range of topics in bioinformatics and computational biology, and were of very high quality. We had a great time in Taipei, enhancing the interactions between many researchers and practioners of bioinformatics, and advancing bioinformatics into a more mature scientific discipline.

Lastly, we wish to express our gratitude to: the authors of the submitted papers, the members of the programme commitee and their subreferees, the members of the organizing committee, the keynote speakers, our generous sponsors, and supporting organizations for making APBC 2006 a great success.

\author{
Tao Jiang \\ Ueng-Cheng Yang \\ Yi-Ping Phoebe Chen \\ Limsoon Wong
}

16 February 2006 


\section{APBC2006 ORGANIZATION}

\section{General Co-Chairs}

Yi-Ping Phoebe Chen (Deakin University)

Wen-Hsiung $\mathrm{Li}$ (University of Chicago)

Limsoon Wong (National University of Singapore)

\section{Organizing Committee}

Jorng-Tzong Horng (National Central University, co-chair)

Cheng-Yan Kao (National Taiwan University, co-chair)

Chih-Jen Chang (Chang-Gang University)

Chuan-Hsiung Chang (National Yang Ming University)

Jung-Hsien Chiang (National Cheng Kung University)

Yi-Fang Chung (National Yang Ming University)

Hsien-Da Huang (National Chiao Tung University)

Hsueh-Fen Juan (National Taiwan University)

Ming-Tat Kao (Academia Sinica)

Chang-Huain Hsieh (National Center for High-Performance Computing)

Feng-Sheng Wang (National Chung Cheng University)

\section{Tutorial Chair}

Wen-Chang Lin (Academia Sinica)

\section{Poster Chair}

Chuan Yi Tang (National Tsing Hua University) 


\section{Programme Committee}

Tao Jiang (University of California, Riverside, USA, and Tsinghua University, China; co-chair)

Ueng-Cheng Yang (National Yang Ming University, Taiwan; co-chair)

Tatsuya Akutsu (Kyoto University, Japan)

Vineet Bafna (University of California, San Diego, USA)

Paola Bonnizoni (Universita' degli Studi di Milano - Bicocca, Italy)

David Bryant (McGill University, Canada, and University of Auckland, New Zealand)

Kun-Mao Chao (Natonal Taiwan University, Taiwan)

Francis Chin (University of Hong Kong, SAR, China)

Ross Coppel (Monash University, Australia)

Michael Cummings (University of Maryland, USA)

Bhaskar DasGupta (University of Illinois, Chicago, USA)

Nadia El-Mabrouk (University of Montreal, Canada)

Janice Glasgow (Queens University, Canada)

Sridhar Hannenhalli (University of Pennsylvania, USA)

Wen-Lian Hsu (Academia Sinica, Taiwan)

Haiyan Huang (University of California, Berkeley, USA)

Ming-Jing Hwang (Academia Sinica, Taiwan)

John Kececioglu (University of Arizona, USA)

Chris Langmead (Carnegie Mellon University, USA)

Sang-Yup Lee (Korea Advanced Institute of Science and Technology, Korea)

Jinyan Li (Institute for Infocomm Research, Singapore)

Jing Li (Case Western Reserve University, USA)

Guohui Lin (University of Alberta, Canada)

Stefano Lonardi (University of California, Riverside, USA)

Henry Horng-Shing Lu (National Chiao Tung Uniersity, Taiwan)

Bin $\mathrm{Ma}$ (University of Western Ontario, Canada)

Shinichi Morishita (University of Tokyo, Japan)

Laxmi Parida (IBM T.J. Watson Research Center, USA)

Kunsoo Park (Seoul National University, Korea)

Christian Pedersen (University of Aarhus, Denmark)

Alexander Schliep (Max Planck Inst. for Mol. Genetics, Germany)

Shoba Ranganathan (Macquarie University, Australia)

Christian Schoenbach (RIKEN, Japan)

Larry Ruzzo (University of Washington, USA)

Lusheng Wang (City University of Hong Kong, SAR, China)

Wei Wang (University of North Carolina, Chapel Hill, USA)

Eric Xing (Carnegie Mellon University, USA)

Michael Zhang (Cold Spring Harbour Labs, USA)

Yang Zhong (Fudan University, China)

Xianghong Zhou (University of Southern California, USA) 


\section{Additional Reviewers}
A. Abu-Zeid
S. Besenbacher
H.L. Chan
L. Chen
I. G. Costa
G. Della Vedova
R. Dondi
D. Dutta
C. Ferretti
R. Fraser
J. Fredslund
B. Georgi
R.S.C. Ho
W.K. Hon
$\mathrm{H}$. $\mathrm{Hu}$
Y. Huang
S. Jensen
H.C.M. Leung
T. Mailund
C. Rangel
S. Sedfawi
W. Rungsarityotin
T.Y. Sung
A. Tam
S. Taylor
S. Teng
C.L. Wang
J. Wang
L. Wang
K.P. Wu
K. Zhang
L. Zhuge

E. Zuveria 
This page intentionally left blank 


\section{CONTENTS}

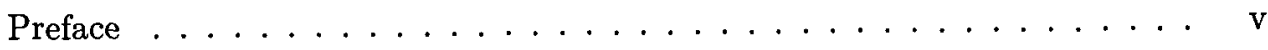

APBC 2006 Organization . . . . . . . . . . . . vii

\section{Keynote Papers}

Wen-Hsiung Li. On the Inference of Regulatory Elements, Circuits and Modules . . . . . . . . . . . . . . . . . 1

Mark A. Ragan. Automating the Search for Lateral Gene Transfer . . . . . 3

Michael S. Waterman. Whole Genome Optical Mapping . . . . . . . . . 5

\section{Contributed Papers}

D.A. Konovalov. Accuracy of Four Heuristics for the Full Sibship Reconstruction Problem in the Presence of Genotype Errors . . . . . . . . 7

P.C.H. Ma \& K.C.C. Chan. Inference of Gene Regulatory Networks from Microarray Data: A Fuzzy Logic Approach . . . . . . . . . . . . 17

C.W. Li, W.C. Chang, \& B.S. Chen. System Identification and Robustness Analysis of the Circadian Regulatory Network via Microarray Data in Arabidopsis Thaliana $\ldots \ldots \ldots \ldots \ldots \ldots \ldots$

P. Horton, K.-J. Park, T. Obayashi, \& K. Nakai. Protein Subcellular Localization Prediction with WoLF PSORT . . . . . . . . . . . . 39

P.-H. Chi \& C.-R. Shyu. Predicting Ranked SCOP Domains by Mining Associations of Visual Contents in Distance Matrices . . . . . . . . . . 49

D. Ruths \& L. Nakhleh. RECOMP: A Parsimony-Based Method for Detecting

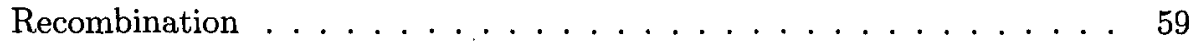

H.-J. Jin, H.-J. Kim, J.-H. Choi, \& H.-G. Cho. AlignScope: A Visual Mining Tool for Gene Team Finding with Whole Genome Alignment . . . . . 69

F.Y.L. Chin \& H.C.M. Leung. An Efficient Algorithm for String Motif Discovery . . . . . . . . . . . . . . . . . . . 79 
Y. Kawada \& Y. Sakakibara. Discriminative Detection of Cis-Acting Regulatory Variation from Location Data . . . . . . . . . . . . . . .

T. Akutsu, M. Hayashida, W.-K. Ching, \& M.K. Ng. On the Complexity of Finding Control Strategies for Boolean Networks . . . . . . . . .

K.F. Chong, K. Ning, H.W. Leong, \& P. Pevzner. Characterization of MultiCharge Mass Spectra for Peptide Sequencing . . . . . . . . . . . . 109

Y. Ma, G. Wang, Y. Li, \& Y. Zhao. EDAM: An Efficient Clique Discovery Algorithm with Frequency Transformation for Finding Motifs . . . . . . 119

M.K. Ng, E.S. Fung, W.-K. Ching, \& Y.-F. Lee. A Recursive Method for Solving Haplotype Frequencies in Multiple Loci Linkage Analysis . . . 129

S. Das, S. Paul, \& C. Dutta. Trends in Codon and Amino Acid Usage in Human Pathogen Tropheryma Whipplei, the Only Known Actinobacteria with Reduced Genome . . . . . . . . . . . . . . . . . . . .

S. Paul, S. Das, \& C. Dutta. Consequences of Mutation, Selection and Physico-Chemical Properties of Encoded Proteins on Synonymous Codon Usage in Adenoviruses . . . . . . . . . . . . . . . . . . . . . . . . 149

Z. Cai, M. Heydari, \& G. Lin. Microarray Missing Value Imputation by Iterated Local Least Squares . . . . . . . . . . . . . . . . . . . 159

S. Thorvaldsen, E. Ytterstad, \& T. Flå. Property-Dependent Analysis of Aligned Proteins from Two Or More Populations . . . . . . . . . . . . 169

L. Shen \& E.C. Tan. A Generalized Output-Coding Scheme with SVM for Multiclass Microarray Classification . . . . . . . . . . . . . 179

D. Ruths \& L. Nakhleh. Techniques for Assessing Phylogenetic Branch Support: A Performance Study . . . . . . . . . . . . . . . . . 187

Y.-P.P. Chen \& Q. Chen. Analyzing Inconsistency Toward Enhancing Integration of Biological Molecular Databases . . . . . . . . . . . . 197

C. Sinoquet. A Novel Approach for Structured Consensus Motif Inference Under Specificity and Quorum Constraints . . . . . . . . . . . 207

C.J. Langmead. A Randomized Algorithm for Learning Mahalanobis Metrics: Application to Classification and Regression of Biological Data . . . . 217 
M.J. Araúzo-Bravo, S. Fujii, H. Kono, \& A. Sarai. Disentangling the Role of Tetranucleotides in the Sequence-Dependence of DNA Conformation: A Molecular Dynamics Approach . . . . . . . . . . . . . . .

Z.-R. Xie \& M.-J. Hwang. A New Neural Network for B-Turn Prediction: The Effect of Site-Specific Amino Acid Preference . . . . . . . . . . 237

S.-S. Huang, D.L. Fulton, D.J. Arenillas, P. Perco, S.J.H. Sui, J.R. Mortimer, \& W.W. Wasserman. Identification of Over-Represented Combinations of Transcription Factor Binding Sites in Sets of Co-Expressed Genes . . 247

C.-T. Chen, H.-N. Lin, K.-P. Wu, T.-Y. Sung, \& W.-L. Hsu. A KnowledgeBased Approach to Protein Local Structure Prediction . . . . . . . . . 257

L.H. Yang, W. Hsu, M.L. Lee, \& L. Wong. Identification of MicroRNA Precursors via SVM .................... 267

M. Shashikanth, A. Snehalatharani, S.K. Mubarak, \& K. Ulaganathan. Genome-Wide Computational Analysis of Small Nuclear RNA Genes of Oryza Sativa (Indica and Japonica) . . . . . . . . . . . . . . 277

X. Han. Resolving the Gene Tree and Species Tree Problem by Phylogenetic Mining . . . . . . . . . . . . . . . . . 287

J. Mañuch, X. Zhao, L. Stacho, \& A. Gupta. Characterization of the Existence of Galled-Tree Networks (Extended Abstract) . . . . . . . . . 297

J. Assfalg, H.-P. Kriegel, P. Kröger, P. Kunath, A. Pryakhin, \& M. Renz. Semi-Supervised Threshold Queries on Pharmacogenomics Time Sequences ......................... 307

K. Arun \& C.J. Langmead. Structure Based Chemical Shift Prediction Using Random Forests Non-Linear Regression . . . . . . . . . . . . . . . 317

M. Huang, X. Zhu, S. Ding, H. Yu, \& M. Li. ONBIRES: Ontology-Based Biological Relation Extraction System . . . . . . . . . . . 327

P.Y. Chan, T.W. Lam, S.M. Yiu, \& C.M. Liu. A More Accurate and Efficient Whole Genome Phylogeny . . . . . . . . . . . . . . . 337

D. Pan \& F. Wang. Gene Expression Data Clustering Based on Local Similarity Combination . . . . . . . . . . . . . . . 353

Author Index . . . . . . . . . . . . . . . . . . . . . . . . . . . . . 